\title{
POLYCULTURAL TRENDS OF UKRAINIAN ETHNO POP FOLK MUSIC OF THE 21st CENTURY
}

\author{
Nelli Samikova \\ Postgraduate Student, Ukrainian National Tchaikovsky Academy of Music, Ukraine \\ e-mail: nellisamikova@gmail.com,orcid.org/0000-0003-2858-5875
}

\section{Summary}

The article highlights the actualization of the cultural and national identification issue in the contemporary world. According to scientists, the preservation of the cultural and national identification in the global environment is the most successful when a polycultural approach is implemented to intercultural communication. The aim of the article is to demonstrate, using a polycultural approach for analysis, how Ukrainian national culture is displayed and popularized through the musical content of the 21 st century. Reactions of video bloggers from YouTube platform became a marker of the popularity of such a cultural product. Using the method of structural analysis, the selected music videos were considered at a verbal level (usage of folk songs lyrics), a visual level (filming the videos in Ukrainian locations, usage of elements of national life, national costumes, etc.) and at an intonational one (usage of national instruments, singing in a national style, etc.). Due to this, it has become possible to highlight polycultural markers in the music content itself and then track the reaction of foreign video bloggers to the polycultural combination of modern music trends with Ukrainian national elements. The presence of such video reactions confirms the demand for polycultural products, transferring it to the category of a trend - what is on time and what is of most interest to a mass consumer. This proves the relevance of further development of the polycultural approach, expanding the scope of its application, as well as the natural perception of polycultural mass consumption products.

Keywords: polyculturalism, cultural identification, national identification, polycultural approach, music video reactions, popular music.

DOI https://doi.org/10.23856/4317

\section{Introduction}

Since the second half of the 20th century intercultural communication has increased significantly due to mass movements, distribution of the unified and publicly accessible "network of networks" - the Internet, improvement and availability of technologies, etc. As a result, a new wave of strengthening intercultural interactions has started, which, in turn, contributed to actualization of sociocultural issues of self-identification, preservation of national traditions, overcoming intercultural and interclass tensions. The latter ones have attained some speed over the past 10 years. To address the issues of reducing tensions in communication and perception of the Other in intercultural communication in the 21 st century, three main approaches were identified - cultural colorblindness, multiculturalism and polyculturalism. Unlike the first two approaches, the latter one is just beginning to be studied and applied in scientific environment. Meanwhile, it seems to be the most optimal for solving contemporary issues of intercultural interactions. Due to significant actualization of intercultural communication and issues of natural existence in the global world of many cultures, polyculturalism has become a kind of trend. A combination of cultural uniqueness and gained experience of past cultural interactions and 
common synergetic cultural products is used today to create an entertainment product both in trendy genres, such as cinematography, animation and music, and by video bloggers on YouTube, TikTok, etc.

The aim of the article is to demonstrate the ongoing polycultural trend in the entertainment sector and how it can help both to preserve the national traditions and cultural uniqueness and to incorporate them into the modern globalizing world. It can be reached by generalization of main scientific studies of polyculturalism, adjustment of its main characteristics to the pop-music industry and analyzing examples from a polycultural perspective.

The novelty of the study lies in application not only of modern samples of Ukrainian ethno-pop and pop-folk music in the study, but also of a perspective of foreign listeners and viewers on unique national and popular world music mix, in order to demonstrate the polycultural trend and its popularity.

The main methods for the study were structural analysis, systemic and polycultural approaches.

\section{Polycultural approach for the consideration of cultures and their self-identification}

The term of polyculturalism was described in 2010 by the researchers Lisa Rosenthal and Sheri R. Levy. In their research they define polyculturalism as an approach that regulates mutual relationships of different cultures in the modern environment. Considering it along with cultural colorblindness and multiculturalism, the researchers conclude that it is the polycultural approach that is the most inclusive for further cultural interactions: "Polyculturalism emphasizes the interconnectedness rather than the separateness of racial and ethnic groups, helping to blur boundaries and allowing people to feel more connected to each other; yet, it does not require ignoring one's racial or ethnic identity or assimilating into or adopting a dominant or common cultural identity in place of one's own identity. $<\ldots>$ Polyculturalism studied in its "neutral" form relates to greater interest in, appreciation for, and comfort with diversity and people from different backgrounds, less support for social dominance or inequality, greater willingness to have contact with people from different racial and ethnic groups, and greater support for related policy attitudes" (Rosenthal \& Levy, 2010: 224-235).

Also, in 2012 the researchers noted how exactly people perceive other cultures in terms of polyculturalism: "People who endorse polyculturalism focus their attention on how cultures have interacted, influenced, and shared ideas and practices with each other throughout history, and how they continue to do so today. Thus, individuals who endorse polyculturalism view people of all racial and ethnic groups as deeply connected to one another through their past and current interactions and mutual influences on each other's cultures. individuals who endorse polyculturalism are focused on the ways that the cultures of all racial and ethnic groups around the world have always been and continue to be influenced by each other and are not, by definition or by extension, focused on developing a superordinate identity or common goals with other groups" (Rosenthal \& Levy, 2012: 2-3).

And the researchers Michael Morris, Chi Yue Chiu and Zhi Liu later mentioned that "Polyculturalism: a network conception of culture in which cultural influence on individuals is partial and plural and cultural traditions interact and change each other" (Morris, Chi Yue Chiu \& Zhi Liu, 2015: 634).

So, polyculturalism has absorbed some positive features of cultural colorblindness and multiculturalism, adding to them similarity of different cultures over time. Thus, the cultures, existing in a multicultural environment (and they are the majority), not only actively interact 
with each other, adopting their experience, but are also able to clearly demonstrate their uniqueness. This becomes the possibility of identification in today's global world.

The topic of cultural identity was arisen for society long before globalization, but before the danger of unification, which was seen (and still is seen) in modern processes, the topic of identity and identification became relevant again. According to scientists, "One of the main aspects that defines the nature of globalization - repressive or liberative - is whether we are allowed to imagine ourselves with multiple identities: flexible, modulated, sometimes superimposed on each other, that in turn creates the cases to conceptualize legitimate and compatible, but not just competitive and threatening, different identities or (even better) different cultures" (Canclini, 2016: 126). Both external, economic and political factors of the present world and the immersion into cyber environment, where everyone can acquire the identity he or she creates, increased the number of "identities" of a person.

That is why, in the contemporary global context and economic, political and corporate confrontations, the issue of the self-identification of cultures and individuals is quite acute. Ukraine, particularly, has been actively implementing a policy of popularization of Ukrainian culture for the last 7 years.

\section{Analysis of Ukrainian popular music}

With polycultural trends of the contemporary world, Ukraine has an opportunity to promote its culture not only in a refined, "museum", format, but also through the inclusion of national traditions in a general multicultural environment. One of the most common methods used for such promotion is popular music. It is important to mention here that "music has always played an important role in human society. If we consider today simply the world of pop music, the manner in which it is effortlessly transcending global barriers and even otherwise extremely difficult linguistic barriers, if we consider the number of people who consume it in some way and millions of economic units consumed in its production and consumption, we are not simply talking about a very big business enterprise" (Garfias, 2004: 1). So, music is a quite universal phenomenon, because it can be enjoyed and appreciated without even understanding principles of its creation or a language which song is created in. Music has become the tool which different cultures can transmit their uniqueness through to the whole world, because it easily absorbs all the changes, correlating with the demands of the contemporary world. "The movement of migrants, refugees, expatriates, nomads, and diasporic people - and the consequent movement of their cultural rituals and expressions alongside with them - as well as the increased flows of culture due to the more advanced communication technologies now available have contributed to changing the meanings of time and space, and thus to the formation of a heterophonic global musical scene in which pastiche, irony, and contradictions are the norm rather than the exception. Music, thanks to the potential for fluid cross-cultural communication its sonorous qualities offer, opens up spaces where authentic experiences may occur even when its production and distribution dynamics are enacted in spite of that possibility" (Kotarba \& Vannini, 2009: 136-137). Therefore, it is the music where it is possible to trace a combination of trends common to different cultures, to observe natural synergy in united product of national past and present universal, which are markers of polycultural. Polycultural in popular music can manifest itself on several levels:

- at a text level

A variety of combination of different cultures is possible at this level. When referring to American or European pop music, a direct reference or a hint of a certain culture is usually 
included in a title of a song or is simply mentioned in lyrics (for example, Rihanna feat. Cold Play "Princess of China", Jain "Makeba", Nicki Minaj "Chun-Li", etc.).

Ukrainian performers also use these techniques, but most often they use texts of folk songs, completely or partially. There are also options when performers slightly modify an original text by adding their own phrases; they replace words of a folk song in such a way that it can still be recognized, or they arrange lyrics in such a way that it resembles a folk song structurally. Also, performers sometimes use certain Ukrainian dialects instead of literary language, so that a song is immediately identified with a certain region of Ukraine.

For example, Ukrainian singer Alina Pash uses all these techniques in her works. In the songs "Oinagori" and "Oigaigai" the singer took the texts of two Ukrainian folk songs "Ой, на горі два дубки” (“Oh There are Two Oaks on the Hill”) and “Очерет-осока" ("Reed, Sedge”) as bases. In addition to directly quoting the text, Alina Pash has partially modified it, adding modern allusions, such as "Вечоронька - годнота, там музики і братва" ("The party is awesome, there are musicians and mates"). The songs also become contemporary due to music styles which these lyrics are applied to. For example, the lyrics of "Oinagori" were put onto reggae music. In her music track "BOSORKANYA" ("A Carpathian Witch") Alina Pash has stylized the lyrics in such a way that it resembled a folk song, using the Transcarpathian dialect in the text and adding mysticism and religiosity to the plot. Similarly, the song "Bitanga" is written exclusively in the Transcarpathian dialect combined with reggae style.

The singer KHAYAT has created his song "OSOKA" ("Sedge") in a similar way. The performer has used many repetitions and short phrases in the lyrics that are inherent in folk songs. The plot of the song is also close to the folk ones - it is about infidelity of a beloved woman and her comparison with the sedge - a symbol of infidelity.

TNMK band ("Tanok Na Maidani Kongo" = "Dance at the Congo Square") has used the Bervy project's recording of singing of the Western Polissia resident - Nadiia Chekun, in one of their newest songs "Янголи" ("Angels"). She is performing a folk lullaby. To be mentioned, the original recording is used only once for the entire song, using its electronic processing for the rest of the music track. The singer's voice was artificially lowered to create more mystic and darker atmosphere, which corresponds to the song theme and its visual images.

The electro-folk Go A band has totally created their newest music track "SHUM" ("Noise") on a basis of folk spring song. The text refers to the mythological forest deity Shum and calls for the arrival of spring and the flowering of trees.

And here's the singer Jerri Heil, who is in the duet with Morphom "Xo Xo Xo \#несеГаляВалю" ("Но ho ho \#AGirlHaliaIsCarryingAGirlValia") has left only rhyme and rhythm from a folk song, completely changing its lyrics. Meanwhile, the popularity of the folk song and the proximity of the musical design help to unmistakably identify the original, even with a complete text change.

- at a visual level

This broadest level involves using both strongly marked elements of different cultures (such as elements of national clothing, architecture, way of life) and elements of subcultures (for example, the appearance of the singer Melanie Martinez is the personification of Japanese style Lolita, and the appearance of the performer Ashnikko vividly broadcasts the anime style) in music videos. This level also includes filming locations, thus representing certain areas of the country as possible tourist attractions (as happened with the Fjaðrargljufur canyon after Justin Bieber's video "I'll Show You” was shot there).

Ukrainian show business most often uses folk costumes, picturesque locations of Ukraine, implements elements of life and national traditions or mythical images in music videos. 
For example, the duet of alyona alyona and KALUSH "Gory" ("Mountains") was shot in the Ukrainian Carpathians with a demonstration of national architecture, as well as folk patterns used in traditional carpet-making. Alina Pash appears in a video for the song "Bitanga" in folk costumes of the Carpathian region. Somewhat stylized costumes and traditions of Ukrainian Easter are reflected in the duet of the performers alyona alyona and Alina Pash "Padlo" ("A Dirtbag").

Instead, KHAYAT uses images of the East national costume in the OSOKA music video, which, combined with lyrics similar to Ukrainian folk songs and the manner of the performance, makes this song polycultural on several levels.

ONUKA band demonstrates even more cultural diversity in their work "ZENIT". Traditional Ukrainian, Japanese, Tibetan and Mexican costumes were used to create the video sequence. According to the soloist Nata Zhyzhchenko, they aimed to reflect the ideas of cosmopolitanism, demonstrating the similarity of elements of Hutsul and Tibetan wedding dress (Butsko, 2019).

ments, etc.)

- at an intonational level (usage of melodic intonations of folk singing; folk instru-

This type of polycultural representation is perhaps the most common among Ukrainian pop singers. Among foreign performers national intonations and folk instruments are used by ones of a certain genre only, whilst in Ukraine it is a common phenomenon used by world-class artists.

In addition to the fact that artists often give concerts accompanied by the National Orchestra of Folk Instruments (for example, Oleg Skrypka from Vopli Vidopliasova band, or ONUKA band), some folk instruments are also interspersed into a musical score quite regularly. Just like in the music tracks of TNMK band "Янголи" ("Angels") and of ONUKA band "ZENIT": a trembita sounds here - a Transcarpathian folk instrument with a length of 2 to 8 meters, which was used by shepherds as a means of communication.

The usage of such instruments as a drymba (a reed plucked folk instrument) and a domra (plucked folk instrument of the lute family) is rare. KHAYAT used a domra to create an oriental ambience, despite the fact the instrument is Ukrainian. Go_A band, in turn, used a drymba both to emphasize the folk spirit of the song and to make the sound of the instrument being fit well into the club-trance style of the music track.

Nevertheless, a sopilka remains the most popular Ukrainian folk instrument among local performers. It is used in their music tracks by Kazka band ("Острів" (Sounds of Chornobyl)), KALUSH feat. alyona alyona ("Mountains"), ONUKA ("ZENIT"), and the sopilka has become a kind of Go_A band's calling card, which foreigners are waiting for in their songs.

Also, some performers, such as KHAYAT and Go_A, perform their songs with folk laryngeal singing that clearly accentuates their belonging to Ukrainian culture. In addition, Go_A in their music track "SHUM" used whooping, calling - sounds that are usually included in the folk songs of spring period to call for spring.

\section{Reaction of foreign listeners (not native speakers) to modern Ukrainian hits}

This polycultural approach to the process of creating a song radically changes presentation of national Ukrainian culture at the world level. If earlier the situation was the following: "Not only American cars, but also films, pop singers, movie stars seem to be the "best" for modern Ukrainian youth... The problem of Ukraine, as well as some other countries, is that cultural and commodity exchange with other countries of the world, unfortunately, has a largely 
one-sided direction" (Sheiko \& Aleksandrova, 2009: 203), now we can see that Ukrainian culture, music particularly, is positively perceived and consumed all over the world.

For example, the song "Cry" by Ukrainian band Kazka was not only broadcasted on radio stations around the world, but also was entered the TOP-10 of the world chart Shazam (Podoliak, 2018). The world-famous fashion designer Elie Saab has chosen the music of DahaBrakha band for his Prêt-à-porter Spring-Summer 2021 fashion show. There are many more examples of positive experiences of Ukrainian performers in the world music environment, but we will focus on the video reactions of listeners posted on YouTube.

So, German video blogger Stephan Boyyy, for the first time reacting to the work of the singer alyona alyona, has differently replied to the artist's two songs. In his video review he evaluated the songs "Завтра" ("Tomorrow") and "Gory". To be mentioned, the second music track "Gory" with visual images of the Ukrainian Carpathians and the involvement of Ukrainian sopilka in the music layer has impressed the blogger much more and has affected him in a positive way - Stephan Boyyy noted the beautiful views, deep message of the lyrics, melody, etc. (Stephen Boyyy, 2020).

Another video blogger from Denmark under the nickname MUSA LOVE L1FE went directly to the duet of alyona alyona and KALUSH "Gori" ("Gory") for his reaction. He noted the pleasant song flow, returned several times to listen to the sopilka, mentioning its originality and accurate application to the music. The most impressive part of the song for MUSA LOVE L1FE was a rap couplet from KALUSH, which he performs in one of the Carpathian Ukrainian dialects (MUSA LOVE L1FE, 2020). Meanwhile, blogger MUSIC TIME from the United States drew attention to all these features of the song as well, moreover mentioning that alyona alyona is one of his favorite artists (MUSIC TIME, 2020). He was also the only YouTuber to listen to the song without subtitles.

The British video blogger MetalHead Reacts, reacting to the song "ZENIT" by ONUKA band has directly pointed up the combination of electronic music with folk instruments and has noticed deep message of the song about the unity of the world, and the visual combination of different cultural images (MetalHead Reacts, 2020). Korean rock singer Jundoy together with YouTuber song wonsub 송원섭 have also recorded a video reaction to the song of the Ukrainian band. They spotlighted the beauty of Ukrainian nature, aesthetic costumes, uniqueness and quality of visual and musical content. Some masks were associated with Korean folk masks. Jundoy and song wonsub 송원섭, previously unfamiliar with the band's work, have noticed its fusion direction, as well as "If it's folk music, they made it popular" (song wonsub 송원섭, 2021).

Due to the presentation of the song "SHUM" as a new song for Eurovision-2021 by Go_A, the reactions to their video are almost the most numerous on YouTube. A video blogger from Greece under the nickname Esc Mike has noted the uniqueness of the whole song due to the combination of electronic music and folk instruments. He also pointed out that Ukrainian language sounds very organic with this music. As a result, he has defined this music track as one of the best contenders not only from Ukraine this year, but also in the history of his reviews of Eurovision songs (Esc Mike, 2021).

Serbian blogger stefanttt also drew attention to the explosive combination of folk and electronic beat in the first version of the Go_A's song. Despite the fact, that the blogger himself was familiar to the folk source of this song and the folklore beginning, he remarked that the musical design, together with folk instruments, is ideal for rave, trance parties. In his review, he emphasized this for his viewers - a combination of "two opposite kingdoms - folklore and electronic, trance music" (stefanttt, 2021). 
All bloggers involved in the Eurovision Hub reactions, representing countries such as the United States, Ireland, Northern Macedonia, Australia, Norway, Spain and Armenia, have also pointed up the novelty of the Go_A's music track, a combination of folk and trance and electronics. Also, everyone noted the originality of sopilka and drymba sounds, and in their opinion, the sopilka complements the musical text very well (Eurovision Hub, 2021).

\section{Conclusions}

After listening to all video reactions from all over the world, it can be observed that Ukrainian culture currently both absorbs all external influences and gradually starts to conquer the world market with its cultural product. It is also clearly demonstrates the establishment of global music environment, where polycultural music, combining both universal musical elements and elements of national culture (at intonation, text and visual levels), successfully exists and is being popularized, becoming a part of the world trend. It makes a positive impression to the Others, those who are not the native ones for a culture (in our case, for Ukrainian one). With the globalization of the world, listeners are able to pick identification markers of a culture out, while perceiving them not as "museumness", but as a bright uniqueness that fits naturally into the world environment, and that is an indication of the polyculturalism.

Application of a polycultural approach to the wider topics like cinematic world or fashion aesthetics with integration of Ukrainian culture and multiple cultural connections to them can be prospective for further research.

\section{References}

Alina Pash (2019). Alina Pash - BOSORKANYA [A Carpathian Witch] (Official Music Video). Retrieved from: https://www.youtube.com/watch? $v=l F F C b N 49 j G 0$ [In Ukrainian]

Alina Pash (2018). Alina Pash-Bitanga. Retrieved from: https://www.youtube.com/watch? $v=$ JyTolNxJ5I [In Ukrainian]

Alina Pash (2019). Alina Pash - Oigaigai [Oh grove, grove]. Retrieved from: https://www. youtube.com/watch? $v=X 7 p Z 5 K x e D n 0$ [in Ukrainian]

Alina Pash (2018). Alina Pash - Oinagori [Oh on the Hill]. Retrieved from: https://www.youtube.com/watch? $v=$ lvOSFrr_N78 [In Ukrainian]

alyona Alyona feat. Alina Pash (2019). alyona alyona \& Alina Pash - Padlo [alyona alyona \& Alina Pash - a Dirtbag]. Retrieved from: https://www.youtube.com/watch? $v=n 8 h i$ IhJNc8o [in Ukrainian]

Butsko D. (2019). ONUKA: «Etnika stala, meni zdaietsia, trokhy spapliuzhenym nyni poniattiam» [ONUKA: "Ethnicity has become, I think, a bit of a dishonored concept today]. LB.ua. Retrieved from: https://lb.ua/culture/2019/12/30/445959_onuka_etnika_stala_meni_zdaietsya. html [in Ukrainian]

Canclini N. G. (2016). Uiavlena hlobalizatsiia [Imaginary globalization]. Lviv: Vydavnytstvo Anetty Antonenko; Kyiv: Nika-Tsentr. [In Ukrainian]

Esc Mike (2021). Go_A - SHUM - [REACTION] - Ukraine Eurovision 2021. Retrieved from: https://www.youtube.com/watch? $v=V Z O M b P D y K O A$

Eurovision Hub (2021). Ukraine | Eurovision 2021 Reaction | Go_A-SHUM| Eurovision Hub. Retrieved from: https://www.youtube.com/watch? $v=c K H 5 c K j d d 8 M$

Garfias R. (2004). Music: the Cultural Context. Osaka: National Museum of Ethnology. 
Go_A (2021). Go_A - SHUM (Official Video). Retrieved from: https://www.youtube.com/ watch? $v=s$ DeMfL8Ib9A [In Ukrainian]

KALUSH feat. alyona Alyona (2019). Gory [Mountains]. Retrieved from: https://www.youtube. com/watch? $v=t X J 2-P g e L V g$ [In Ukrainian]

KAZKA feat. RUNSTAR (2020). KAZKA x RUNSTAR - Ostriv [Sounds of Chernobyl]. Retrieved from: https://www.youtube.com/watch? $v=O D 8 I 8 P B i q 1 A$ [in Ukrainian]

KHAYAT (2019). KHAYAT - OSOKA [SEDGE] (official video). Retrieved from: https://www. youtube.com/watch? $v=D N d \_H \_1 Z J g w$ [in Ukrainian]

Kotarba J. A., Vannini Ph. (2009). Understanding Society through Popular Music. New York; London: Routledge. Taylor\&Francis Group.

MetalHead Reacts (2020). METALHEAD REACTS to "Zenit" by Onuka. Retrieved from: https://www.youtube.com/watch? $v=Q Y L B M U U M m s k \& t=447 \mathrm{~s}$

Morris M. W., Chi Yue Chiu, Zhi Liu (2015). Polycultural Psychology. "Annual Review of Psychology”, Vol. 66, pp. 631-659. DOI: 10.1146/annurev-psych-010814-015001

Morphom \& Jerry Heil (2020). Kho Kho Kho \#neseHaliaValiu [Ho ho ho \#AGirlHaliaIsCarryingAGirlValia]. Retrieved from: https://www.youtube.com/watch? $v=9 S T l v S W Q t j 8$ [In Ukrainian]

MUSA LOVE LIFE (2020). KALUSH feat Alyona Alyona - Gory | REACTION!!! Retrieved from: https://www.youtube.com/watch? $v=t b g x S o 6 R K Y Q \& t=407 \mathrm{~s}$

MUSIC TIME (2020). KALUSH feat. alyona alyona - Gory REACTION. Retrieved from: https://www.youtube.com/watch? $v=O D w T P r e--5 s \& t=95 \mathrm{~s}$

ONUKA Retrieved from

Podoliak, I. (2018). 10 Ukrainian Songs of 2018. Retrieved from: https://www.ukrainianlessons.com/10-ukrainian-songs-of-2018/

Rosenthal, L., Levy, Sh. R. (2010). The Colorblind, Multicultural, and Polycultural

Ideological Approaches to Improving Intergroup Attitudes and Relations. "Social Issues and Policy Review”, Vol. 4, No. 1, pp. 215-246.

Rosenthal, L., Levy, Sh. R. (2012). The Relation Between Polyculturalism and Intergroup Attitudes Among Racially and Ethnically Diverse Adults. "Cultural Diversity and Ethnic Minority Psychology”, Vol. 18, No. 1, pp. 1-16. DOI: 10.1037/a0026490

Sheiko, V., Aleksandrova, M. (2009). Kultura ta tsyvilizatsiia v istoryko-kulturnii dumtsi Ukrainy $v$ dobu hlobalizatsii [Culture and civilization in the ukrainian historical and cultural thought in the age of globalization]. Kyiv: Instytut kulturologii AMU. [in Ukrainian]

Song wonsub 송원섭 (2021). Reakcija korejskogo rok-pevca, vpervye uvidevshego ONUKA-ZENIT !!!! [Reaction of Korean rock-singer, who saw ONUKA-ZENIT for the first time]. Retrieved from: https://www.youtube.com/watch? $v=$ howVNCVW7VI\&t $=140$ s. [In Korean with Russian subtitles]

Stefanttt (2021). SERBIAN DUDE REACTS TO EUROVISION 2021 I UKRAINE : Go_ASHUM. Retrieved from: https://www.youtube.com/watch? $v=4 Y$-WOUQpcmE

Stephan Boyyy (2020). German reacting to songs by Alyona Alyona \& KALUSH. Retrieved from: https://www.youtube.com/watch? $v=6 U s f 5 C Q f d S O \& t=684 \mathrm{~s}$

TNMK (2018). TNMK - Ianholy (official video) [DACS - Angels (official video)]. Retrieved from: https://www.youtube.com/watch?v=0uOpG98Z0R0 [in Ukrainian] 